J. Clin. Chem. Clin. Biochem.

Vol. 20, 1982, pp. 291-294

\title{
Lactate Dehydrogenase Isoenzyme 1 in the Diagnosis of Myocardial Infarction
}

\author{
By N. Fogh-Andersen \\ Department of Clinical Chemistry,
}

P. Sфrensen

Department of Cardiology,

\section{J. Mфller-Petersen}

Department of Clinical Chemistry and

T. Ring

Department of Cardiology

Aalborg Hospital, Aalborg, Denmark

(Received August 3/November 23, 1981)

Summary: A new immunochemical method for the measurement of lactate dehydrogenase isoenzyme 1 (LDH-1) was used on 113 consecutively admitted patients with suspected myocardial infarction. Using WHO's criteria and our routine program 49 were classified as having myocardial infarction and 64 as having no myocardial infarction. LDH-1 was better than total lactate dehydrogenase in discriminating between patients with and without myocardial infarction ( $p<0.02)$, and the efficiency (the number of correct classifications divided by the total number of analyses) on day 2-3 equalled that from the literature for CK-MB on day 1 . Total lactate dehydrogenase and LDH-1 are supplemental to creatine kinase (CK) and CK-MB, while aspartate aminotransferase may be omitted in the diagnosis of myocardial infarction. Determination of the ratio of LDH-1 to total lactate dehydrogenase offered no advantage.

\section{Lactatdehydrogenase-Isoenzym 1 in der Diagnostik des Herzinfarkts}

Zusammenfassung: Zur Bestimmung von Lactatdehydrogenase-İsoenzym 1 (LDH-1) bei 113 mit Verdacht auf Myokardinfarkt eingewiesenen Patienten wurde eine neue immunchemische Methode angewandt. Aufgrund der WHOKriterien und unseres Routineprogramms wurden 49 Patienten als mit Herżinfarkt und 64 als ohne Herzinfarkt klassifiziert. Für die Diskriminierung Myokardinfarkt/kein Myokardinfarkt war LDH-1 besser $(p<0,02)$ als Gesamt-Lactatdehydrogenase geeignet und die Effizienz (korrekte Klassifikation/Gesamtzahl der Analysen) an Tag 2-3 entsprach der aus der Literatur für CK-MB an Tag 1. Gesamt-Lactatdehydrogenase und LDH-1 ergänzen Kreatinkinase (CK) und CK-MB, während Aspartataminotransferase für die Diagnostik des Myokardinfarkts entfallen kann. Die Bestimmung des Verhältnisses LDH-1/Gesamt-Lactatdehydrogenase bringt keinen Vorteil.

\section{Introduction}

Lactate dehydrogenase (LDH) is a tetrameric molecule consisting of four subunits of either $H$ (heart) or $M$ (muscle) type. Various combinations of $\mathrm{H}$ and $\mathrm{M}$ yield five different tetramers. Lactate dehydrogenase isoenzyme 1 (LDH-1) migrates fastest towards the anode during enzyme-electrophoresis, and it consits of four $\mathrm{H}$ subunits. After heart muscle damage serum LDH-1 particularly increases, and it is used to diagnose acute myocardial infarction. In addition to enzyme-electrophoresis, differences in substrate affinities, temperature and $\mathrm{pH}$ sensitivity, inhibitors and chromatography have been used. Separation of the isoenzymes by these other methods is incomplete, and electrophoresis followed by enzyme staining is time-consuming and tedious. The purpose of the present study is to examine a commercially available method for the measurement of LDH-1 after immunochemical removal of the other isoenzymes, and to apply the analysis to the diagnosis of myocardial infarction. 


\section{Patients}

We investigated all patients with suspected myocardial infarction admitted to the department of cardiology during December 1980. The department receives all patients with suspected myocardial infarction from a district with 181439 inhabitants. 113 patients, 31 women and $82 \mathrm{men}$, were admitted with this diagnosis. The mean ages of the women and the men were 70 and 60 years, respectively.

The diagnosis of definite myocardial infarction was based on WHO's criteria (1), which demand

1) a typical ECG or

2) an equivocal ECG with definite enzymes or

3) a typical history with definite enzymes or

4) a positive post-mortem.

Patients not fulfilling WHO's demands were classified as no myocardial infarction. Of the 113 patients, 49 had myocardial infarction and 64 had no myocardial infarction. There were no significant age or sex differences between the two groups, and the prevalence of myocardial infarction is the usual for a cardiology department.

40 of the 49 patients with myocardial infarction were admitted on the same day as the onset of chest pain, four between 24 and $48 \mathrm{~h}$, three between 48 and $72 \mathrm{~h}$, and two more than three days after the pain started.

The 64 patients without myocardial infarction shared the following diagnoses: 33 angina pectoris, 11 arrhythmias, 9 heart failure, 4 bronchitis, 3 pneumonia, 3 peptic ulcer, 2 acute pericarditis, 2 pneumothorax, 2 alcohol abuse, 1 pulmonary embolism, 1 lung neoplasm, 15 musculoskeletal pains, 2 anxiety neurosis, and 3 miscellaneous.

\section{Methods}

The patients went through the routine examination program of the department. The blood samples for total lactate dehydrogenase and aspartate aminotransferase were drawn on admission and in the morning of the 1., 2., 3., 5., and 7. days. If the admission coincided with the morning sampling on day 1 , only one sample was taken that day.
Total lactate dehydrogenase and LDH-1 were measured simultaneously, and the result of the LDH-1 determination was not known by the cardiologist. The diagnosis was not known by the laboratory. All enzyme activities were measured with a LKB 2086 kinetic analyzer (3).

We measured LDH- 1 as the residual enzyme activity after immunochemical removal of the other isoenzyme fractions. $100 \mu l$ serum was used. Gōat antibody to $M$ subunits wàs added, followed by donkey anti-goat immunoglobulin bound to inert particles (2). (Isomune-LD, Roche Diagnostics, Nutley, NJ 07110). After centrifuging, only LDH=1 (consisting of four $H$ subunits) remained in the supernatant. Samples with total lactate dehydrogenase above $1000 \mathrm{U} / 1$ were diluted before the addition of antibody. Enzyme-electrophoresis in agarose gel with subsequent staining and visual estimate (4) was performed as an accuracy control.

Paired t-test was used to evaluate differences between paired observations.

\section{Results}

Figure 1 shows the primary LDH:1 data. Discriminatory or cut-off limits were chosen to maximize the efficiency on each day following the myocardial infarction. By efficiency is meant the number of correct divided by the total number of classifications. We regard wrong positive and wrong negative diagnoses as equally bad, in agreement with common practice (5). The chosen limits are shown in table 1 .

Tables 2-4 show the efficiency, specificity, and sensitivity, respectively, for total lactate dehydrogenase and LDH-1 on each day. (The specificity is the ratio of negatives to total samples from patients without myocardial infarction, and the sensitivity is the ratio of positives to total samples from patients with myiocardial infarction $(5,6))$. The efficiency is significantly higher for LDH-1 than for total lactate dehydrogenase

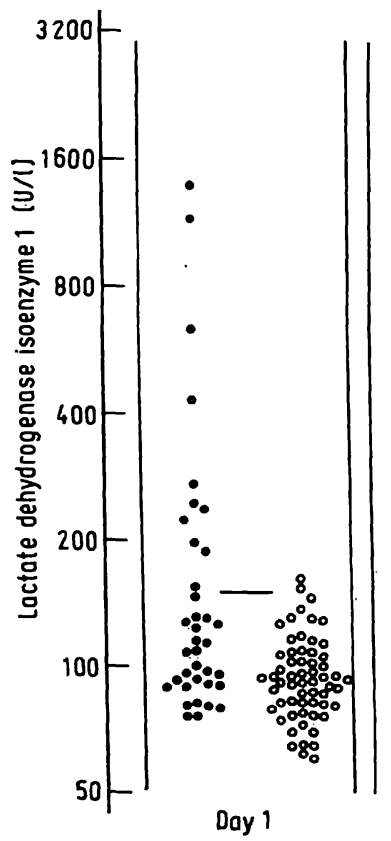

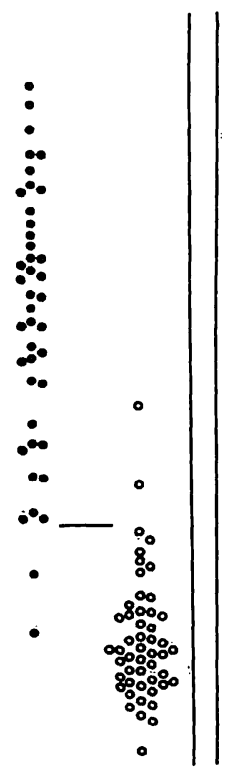

Day 2

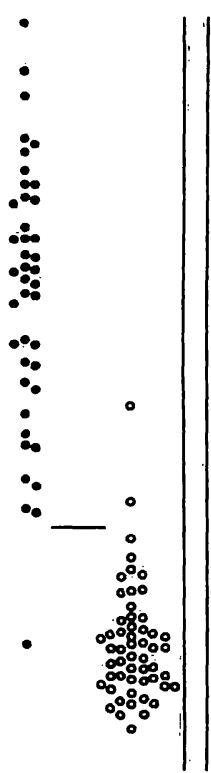

Doy 3

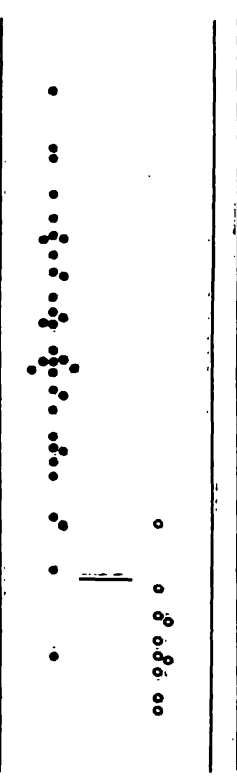

Day 5

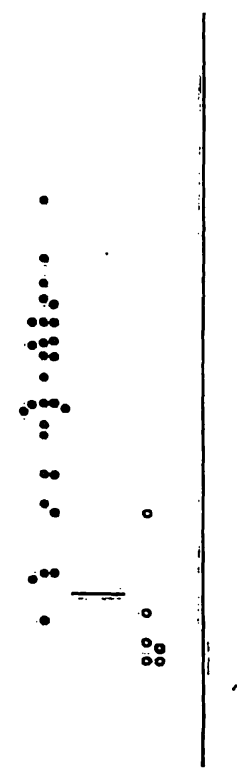

Day 7

Fig. 1. Distribution of the LDH-1 results from patients with $(\bullet)$ and without myocardial infarction (o) (log scale) on each day following the acute attack, with the chosen discrimination values. 
Tab. 1. Discriminatory or cut-off limits for LDH-1 and total lactate dehydrogenase (LDH) $\left(\mathrm{U} / 1,37^{\circ} \mathrm{C}\right)$ on each day after the onset of symptoms. The limits are chosen to give the maximum number of correct classifications on each day. The cut-off limits for total lactate dehydrogenase differ from the usual upper limit of normal $\left(450 \mathrm{U} / 1,37^{\circ} \mathrm{C}\right)$, because some patients without myocardial infarction had slightly elevated levels while patients with myocardial infarction had transient high values.

\begin{tabular}{llllll}
\hline & Day 1 & Day 2 & Day 3 & Day 5 & Day 7 \\
\hline LDH-1 & 152 & 188 & 190 & 145 & 130 \\
Total LDH & 483 & 590 & 710 & 560 & 500 \\
\hline
\end{tabular}

Tab. 2. The efficiency of LDH-1 and total lactate dehydrogenase $(\mathrm{LDH})$ (the incidence of true positives and true negatives among all results of the test).

\begin{tabular}{llllll}
\hline & $\begin{array}{l}\text { Day 1 } \\
\mathrm{n}\end{array}$ & $\begin{array}{l}\text { Day 2 } \\
96\end{array}$ & $\begin{array}{l}\text { Day 3 } \\
99\end{array}$ & $\begin{array}{l}\text { Day 5 } \\
45\end{array}$ & $\begin{array}{l}\text { Day 7 } \\
35\end{array}$ \\
\hline LDH-1 & 0.73 & 0.96 & 0.97 & 0.96 & 0.94 \\
Total LDH & 0.72 & 0.93 & 0.91 & 0.91 & 0.86 \\
\hline
\end{tabular}

Tab. 3. The specificity of LDH-1 and total lactate dehydrogenase (LDH) (the incidence of results below the cutoff limit among patients without myocardial infarction). The number of analyses on day five and seven are small because many of the patients were discharged or transferred to other departments.

\begin{tabular}{llllll}
\hline n & $\begin{array}{l}\text { Day 1 } \\
63\end{array}$ & $\begin{array}{l}\text { Day 2 } \\
54\end{array}$ & $\begin{array}{l}\text { Day 3 } \\
57\end{array}$ & $\begin{array}{l}\text { Day 5 } \\
10\end{array}$ & $\begin{array}{l}\text { Day 7 } \\
6\end{array}$ \\
\hline LDH-1 & 0.98 & 0.96 & 0.96 & 0.90 & 0.83 \\
Total LDH & 0.86 & 0.93 & 0.95 & 0.90 & 0.67 \\
\hline
\end{tabular}

Tab. 4. The sensitivity of LDH-1 and total lactate dehydrogenase (LDH) (the incidence of results above the cutoff limit among patients with myocardial infarction).

\begin{tabular}{llllll}
\hline & Day 1 & Day 2 & Day 3 & Day 5 & Day 7 \\
$\mathrm{n}$ & 37 & 42 & 42 & 35 & 29 \\
\hline LDH-1 & 0.30 & 0.95 & 0.98 & 0.97 & 0.97 \\
Total LDH & 0.49 & 0.93 & 0.86 & 0.91 & 0.90 \\
\hline
\end{tabular}

considering all days $(p<0.02)$. Five patients with subendocardial infarctions had total làctăte dehydrogenase below the cut-off limit on day 2 or 3 , but elevated LDH-1. Three patients with heart failure without myocardial infarction had elevated total lactate dehydrogenase, but LDH-1 below the cut-off limit. One patient with ventricular fibrillation without myocardial infarction underwent direct current cardioversion and had elevated total lactate dehydrogenase and LDH-1.

The usual upper limit for total lactate dehydrogenase of $450 \mathrm{U} / 1\left(37^{\circ} \mathrm{C}\right)$ gives a lower efficiency than the chosen cut-off limits $(0.77$ vs. 0.86 , respectively, $\mathrm{p}<0.02$ ). Both aspartate aminotransferase and the ratio of LDH-1 to total lactate dehydrogenase had lower efficiencies than total lactate dehydrogenase, even when the cut-off limits were chosen for maximum efficiency.

The imprecision (SD) of the LDH-1 measurement was $4.3 \mathrm{U} / 1$ in the range $100-200 \mathrm{U} / 1(\mathrm{CV}, 3 \%)$ and $9.8 \mathrm{U} / 1$ in the range $200-1000 \mathrm{U} / 1(\mathrm{CV}, 1.5 \%)$, both calculated from $\mathbf{4 0}$ duplicate measurements. Day-to-day imprecision was $10 \mathrm{U} / 1(\mathrm{CV}, 2 \%)$, as calculated from 20 daily measurements on a control serum ("K 79", from the Danish Society for Clinical Chemistry).

The accuracy was visually evaluated by enzyme-electrophoresis. The capacity of the antibody to inhibit the other isoenzyme fractions was determined by diluting serum from a patient with myocardial infarction and heart failure with liver stasis. Figure 2 shows serum with and without added antibody after dilution to a total lactate dehydrogenase of $2600 \mathrm{U} / 1$, which is the approximate capacity of the antibody when the enzyme is of mainly hepatic origin. Our practice of diluting serum with total lactate dehydrogenase above $1000 \mathrm{U} / 1$ thus assures the complete removal of all enzyme activity other than LDH-1.

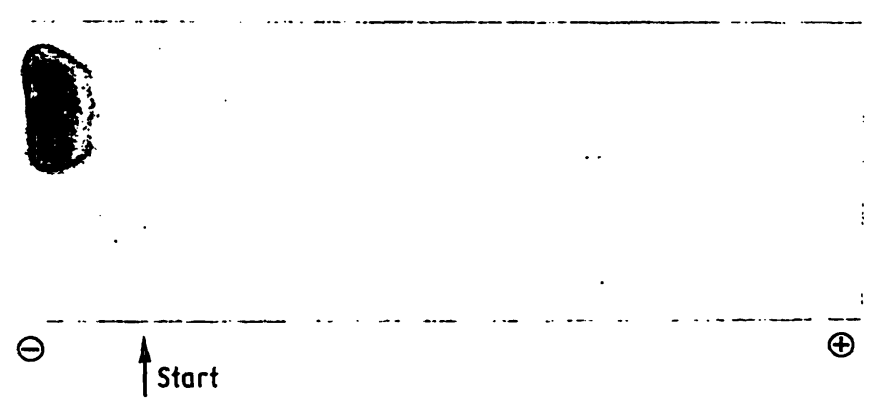

Fig. 2. Enzyme-electrophoresis showing lactate dehydrogenase (LDH) isoenzymes before and after the immunochemical LDH-1 procedure with antibody against $M$ subunits. The patient had myocardial infarction and heart failure with liver stasis, and serum was diluted to a total lactate dehydrogeñase of $2600 \mathrm{U} / 1\left(37^{\circ} \mathrm{C}\right)$ to determine the capacity of the antibody. LDH-1 lies to the right, and it is unaltered because it consists of four $\mathrm{H}$ subunits. LDH-2 is barely visible, and the remaining three isoenzyme bands have been completely removed.

\section{Discussion}

The diagnosis of myocardial infarction is based on patient history, ECG and routine laboratory data. WHO's criteria give accurate and congruent clinical diagnoses (7), and we do not think that the criteria should be changed or the enzyme data be given more weight. The future discrimination between patients with and without myocardial infarction may however be improved with better use and choice of enzyme investigations. With this in mind we examined the value of LDH-1 in a prospective study and compared it to the value of total lactate dehydrogenase, aspartate aminotransferase, and the ratio of $\mathrm{LDH}-1$ to total lactate dehydrogenase. 
We do not yet routinely measure creatine kinase isoenzyme (CK-MB), but when we do, a supplementary test will be needed for the patients who are admitted more than $24 \mathrm{~h}$ after their myocardial infarction, when CK-MB may have normalized $(8-12)$. In the present study, this was the case for 9 out of 49 patients. Total lactate dehydrogenase and LDH-1 are an obvious choice, and the study confirms that the efficiency of LDH-1 $(2,13) 2-3$ days after the myocardial infarction is as high as others have found for CK-MB in the first $24 \mathrm{~h}$ (14). The discriminatory or cut-off limits differ from the usual upper normal limit, and they change with time after the myocardial infarction. Theoretically the time dependency is a draw back, but usually the point of time of the myocardial infarction is known with certainty. The patients with myocardial infarction had transient elevated levels, while some patients without myocardial infarction had elevated but constant enzyme levels. The efficiency depends on the chosen upper limit, and an optimum was reached by considering the diagnostic situation. Aspartate aminotransferase and the ratio of LDH-1 to total lactate dehydrogenase both had lower efficiencies than total lactate dehydrogenase, which questions their use in the diagnosis of myocardial infarction (8).

The patient with ventricular fibrillation who underwent direct current cardioversion had both elevated total lactate dehydrogenase and LDH-1, but not myocardial infarction according to the WHO's criteria.

\section{References}

1. World Health Organization (1979) Myocardial infarction community registers, results of a WHO international collaborative study coordinated by the regional office for Europe. Copenhagen.

2. Usategui-Gomez, M., Wicks, R. W. \& Warshaw, M. (1979) Clin. Chem. 25, 729-734.

3. The Committee on Enzymes of the Scandinavian Society for Clinical Chemistry and Clinical Physiology (1974)

Scand. J. Clin. Lab. Invest. 33, 291-306.

4. Gerhardt-Hansen, W. (1968) Dan. Med. Bull. 15, Suppl. I.

5. Galen, R. S. \& Gambino, S. R. (1975) Beyond normality, the predictive value and efficiency of medical diagnoses. John Wiley \& Sons, New York.

6. Hofvendahl, S., Gerhardt, W., Ljungdahl, L. \& Olsen, J. S. (1978) Acta Med. Scand., Suppl. 623, 117-120.

7. Hansen, B. F. (1980) Dan. Med. Bull. 27, 113-117.

8. Galen, R. S., Reiffel, J. A. \& Gambino, S. R. (1975)

J. Amer. Med. Ass. 232, 145-147.

9. Kraft, J., Aastrup, H. \& Schrфder, P. (1978) Acta Med. Scand. 203, 167-174.

10. Gann, D., Cabello, B., DiBella, J., Rywlin, A. M. \& Samet, P. (1978) South. Med. J. 71, 1459-1462.
Others have found unchanged LDH-1 following direct current cardioversion (15). It is possible that some patients with coronary heart disease classified as not having myocardial infarction would have small infarctions detected by more sensitive means such as frequent CK-MB determinations or myodcardial scanning $(16,17)$. The prognosis quoad vitam after hospitalization with coronary heart disease does not depend on the presence or absence of myocardial infarction (17), but LDH-1 may be useful in the immediate prognosis and the estimation of infarction size $(18,19)$.

LDH-1 determination with the immunochemical technique is easy to perform, and the analysis has satisfactory precision and accuracy. Disease in organs other than the heart will probably cause an increase in LDH-1 since some other organs also contain much LDH-1 (e.g. erythrocytes, kidney and brain); but the analysis is still relevant in the diagnosis of myocardial infarction, because the prevalence of such diseases is low amongst patients admitted with suspected myocardial infarction $(20,21)$. The specificity of total lactate dehydrogenase can be increased by using higher cut-off limits, but LDH-1 still has a higher efficiency. A future analysis program for patients with suspected myocardial infarction should consist of CK-MB and LDH-1, and the aspartate aminotransferase analysis may be omitted.

11. Frohlich, J., Brosseuk, A., Grant, A. \& McLennan, M. (1978) Clin. Biochem. 11, 232-234.

12; Vasudevan, G., Mercer, D. W. \& Varat, M. A. (1978) Circulation 57, 1055-1057.

13. Leung, F. Y. \& Henderson, A. R. (1979) Clin. Chem. 25, $209-211$.

14. Lott, J. A. \& Stang, J. M. (1980) Clin. Chem. 26, $1241-1250$.

15. Reiffel, J. A., McCarthy, D. M. \& Leahey, E. B. (1979) Am. Heart J. 97, 810-811.

16. Przyjemsky, C. J. (1980) N. Engl. J. Med. 303, 1364-1365.

17. Schroeder, J. S., Lamb, I. H. \& Hu, M. (1980) N. Engl. J. Med. 303, 1-5.

18. Savory, D. J. \& Pryce, J. D. (1980) Lancet II, 1375-1376.

19. Bart, B. Y. \& Pivovarov, V. A. (1979) Kardiologiia 19, 91-95.

20. Cembrowsky, G. (1981) Clin. Chem 27, 342.

21. Pragay, D. A., Fan, P., Toppin, M. \& Gotthelf, J. (1981) Clin. Chem. 27, 355-356.

Dr. N. Fogh-Andersen Department of Clinical Chemistry Herlev Hospital

DK-2730 Herlev 